\section{Type II myocardial infarction and latent LVOT obstruction due to Systolic Anterior Motion of mitral valve}

\author{
Makrides Constantinos* \\ Limassol Cardiology Centre, Cyprus
}

\section{Abstract}

Left ventricular outflow tract obstruction is a well-recognized feature in hypertrophic cardiomyopathy but can occur in other clinical scenarios when anatomically susceptible heart is subjected to permissive physiological conditions that provoke systolic anterior motion of the mitral valve (SAM): ie, reduced preload, increased inotropic state, and decreased afterload.

This report describes a case of hemodynamically significant latent LVOTO that was associated with hypotension, syncope, acute myocardial ischemic ECG changes, and an increase in cardiac enzymes. (Type II myocardial infarction) in a non HCM patient with excessive anterior mitral valve tissue.

\section{More Information}

*Address for Correspondence: Dr. Makrides Constantinos, MD, FESC, Limassol Cardiology Centre, Cyprus, Tel: +35799667938; Email: makridesconstantinos@gmail.com

Submitted: 25 July 2019

Approved: 31 July 2019

Published: 02 August 2019

How to cite this article: Constantinos M. Type II myocardial infarction and latent LVOT obstruction due to Systolic Anterior Motion of mitral valve. Arch Case Rep. 2019; 3: 017-020. https://doi.org.10.29328/journal.acr.1001015

Copyright: (c) 2019 Constantinos M. This is an open access article distributed under the Creative Commons Attribution License, which permits unrestricted use, distribution, and reproduction in any medium, provided the original work is properly cited

Check for updates

\section{Introduction}

Left ventricular (LV) outflow tract (LVOT) obstruction (LVOTO) caused by systolic anterior motion (SAM) and septal contact of the mitral valve is an important cause of hypotension, syncope and exertional symptoms in hypertrophic cardiomyopathy, but can also occur in non-HCM patients during either provocation testing (eg using Valsalva manoeuvre, glyceryl trinitrate, dobutamine infusion or exercise stress).

We describe a case of a presumably exercise associated significant latent LVOT obstruction due to SAM that resulted in syncope, hypotension and type II myocardial infarction (ie ischaemic myocardial injury in the context of a mismatch between oxygen supply and demand) in a non HCM anatomically susceptible for LVOTO patient that was partially reproduced during dobutamine stress echo.

\section{Case Report}

A 42 year old athlete presented to our first aid department after a syncopal episode following intense exercise.

On examination he had excessive sweating, and appeared dehydrated with flat neck veins while a mid-systolic III/VI murmur best heard over the aortic valve area was audible.

His heart rate was $99 / \mathrm{min}$ and he was hypotensive with a blood pressure of $76 / 44 \mathrm{mmHg}$.
A normal saline infusion was immediately initiated, while an ECG was performed even though the patient strangely reported no chest pain whatsoever. The electrocardiogram demonstrated significant inferolateral ST segment depression (Figure 1) associated - as it was later evident - with an increase in serum troponin $(3476 \mathrm{pg} / \mathrm{ml})$. It is of notice that the troponin levels rose to $4476 \mathrm{pg} / \mathrm{ml}$ the next day and began to decline 48-72 hours after the event, showing thus a typical rise and fall of cardiac biomarkers after an acute coronary event. It is also important to notice that the patient's renal function was within normal levels (S Creatinine $0.86 \mathrm{mg} / \mathrm{dl}$ ).

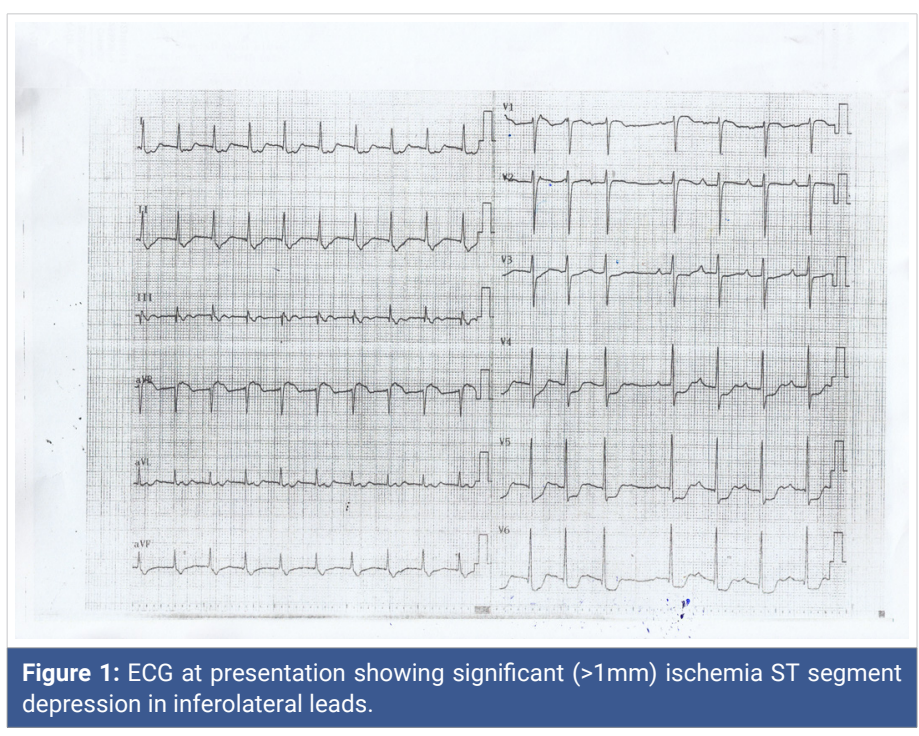


As the patient received high volume rehydration, the patient's blood pressure returned to normal, and after approximately 10 minutes, the ECG changes became alleviated (Figure 2) while no systolic murmur was heard. At this time a thransthoracic echocardiography study was performed which showed normal LV wall thickness and internal dimension with systolic anterior motion of the mitral valve (SAM) (Figure 3) in the absence of subaortic valve obstruction while the patient's $3^{\text {rd }}$ ECG (Figure 4) showed complete resolution of the ST- segment changes. He was treated as an acute coronary syndrome with standard medication and was transferred for coronary angiography which demonstrated no coronary artery disease.

On the basis of the history of the patient, the following days he underwent provocation testing with dobutamine using the standard protocol [1].

Beta-blocker was withheld on the morning of the stress test and the patient was fasted for $>8 \mathrm{~h}$ prior to the test. The infusion was discontinued when the patient reached the target HR of $80 \%$ of the age-predicted maximum HR and at which point a severe LVOT obstruction was induced due to systolic anterior motion of the mitral valve with a peak systolic gradient of $100 \mathrm{mmHg}$ (Figures 5,6). This resulted in sudden hypotension, presyncope, diaphoresis and dyspnoea, symptoms similar to those experienced by the patient during the acute phase of his presentation.

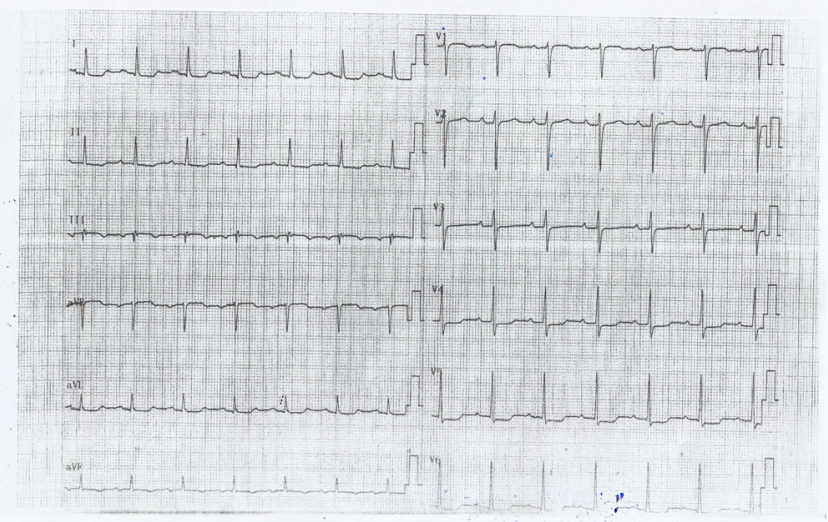

Figure 2: ECG showing alleviation of the ST segment depression in inferolateral leads 5 minutes after rehydration of the patient.

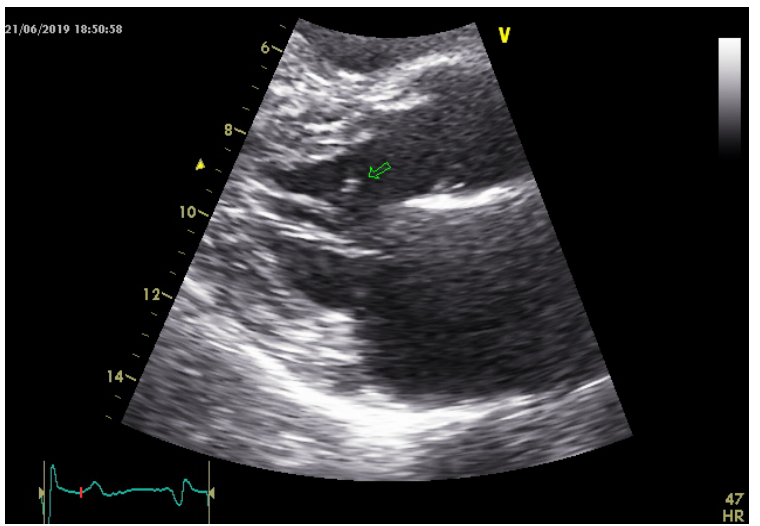

Figure 3: Systolic anterior motion of the mitral valve with no LVOT obstruction.

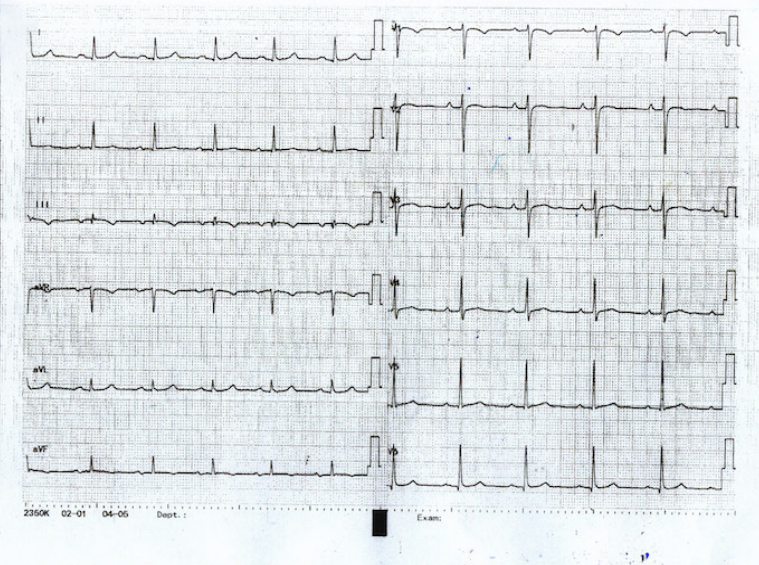

Figure 4: ECG showing complete resolution of the ischemic ST changes.

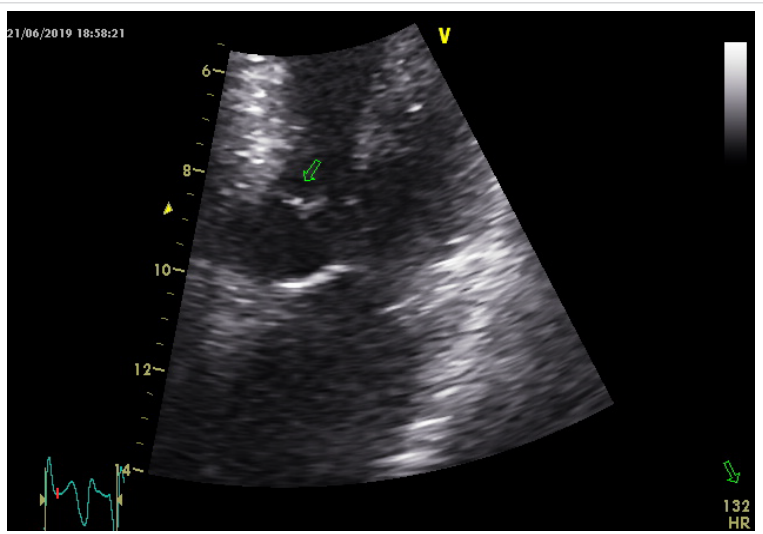

Figure 5: Severe latent LVOT obstruction due to SAM after dobutamine infusion.

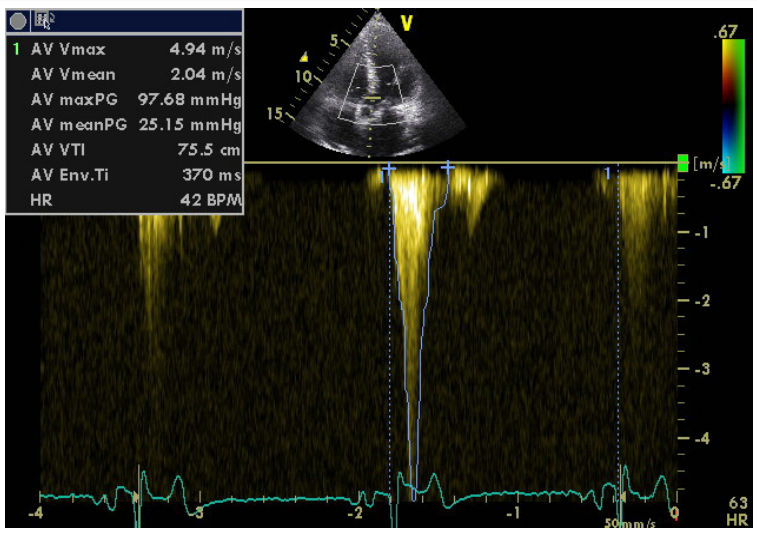

Figure 6: Severe latent LVOT obstruction due to SAM after dobutamine infusion.

At the same time we observed mild ST segment changes in the inferolateral leads suggesting that the patient may potentially suffer from LVOT obstruction under certain conditions such as intensive exercise and/or dehydration, which at a higher degree can lead to severe hypotension and type II myocardial infarction (ie ischaemic myocardial injury in the context of a mismatch between oxygen supply and demand).

After discontinuation of the dobutamine infusion and 
prompt hydration of the patient the LVOT obstruction was resolved and no gradient was evident (normal LVOT gradients recorded $-8 \mathrm{mmHg}$ ).

The patient was treated with beta-blockers and emphasize was given on the importance of proper hydration while he was instructed to avoid intensive exercise. There is up to date (1 year after the event), no recurrence of his symptoms.

\section{Discussion}

Systolic anterior motion (SAM) is defined as displacement of the distal portion of the anterior leaflet of the mitral valve toward the left ventricular outflow area (LVOA) [2]. SAM can occur not only in patients with hypertrophic cardiomyopathy which is one of the hallmark echocardiographic findings, but also in patents without the disease [3] and is a well-recognized cause for unexplained sudden hypotension [4].

Systolic anterior motion of the mitral valve can be graded echocardiographically:

I. No mitral leaflet-septal contact, minimum distance between the mitral valve and the ventricular septum during systole $=10 \mathrm{~mm}$;

II. No mitral leaflet-septal contact, minimum distance between the mitral valve and the ventricular septum during systole $<10 \mathrm{~mm}$;

III. Brief mitral leaflet-septal contact $(<30 \%$ of systole time);

IV. Prolonged mitral leaflet-septal contact $(>30 \%$ of systole time).

Predisposing factors that cause SAM are:

(1) excessive anterior or posterior leaflet tissue;

(2) any anatomical or surgical translocation of the mitral valve anteriorly;

(3) aortomitral angle $<120^{\circ}$;

(4) pathological or post-surgical correction elongation of the anterior leaflet;

(5) annular undersizing in mitral valve repair;

(6) chordal anomalies such as elongation;

(7) surgical chordal interventions such as transection, translocation, and reimplantation;

(8) anterior and medial displacement of the papillary muscles;

(9) bulging subaortic septum;

(10) absolute height of the posterior leaflet $(>1.5 \mathrm{~cm})$;
(11) anterior to posterior leaflet height ratio $(<1.4)$; and

(12) minimum distance from the coaptation point to the septum (C-Sept, $<2.5 \mathrm{~cm}$ )

Paradoxically, SAM is uncommon in post-AVR patients operated for aortic regurgitation due to dilated LV with increased distance between mitral valve and LVOT and compensatory hypervolemia seen in these patients [5].

Also, takotsubo cardiomyopathy can present with SAM and left ventricular outflow tract obstructions because of mid and apical hypokinesia and compensatory basal hypercontractility [6].

It is also reported that patients with diabetes mellitus and hypertension may manifest SAM in the context of LV hypertrophy due to hyperdynamic state by raised $\beta$-adrenoreceptor sensitivity [7].

Dobutamine stress echocardiography has also been reported to cause SAM by alteration of pathoanatomical features of mitral valve [8].

It is like unmasking of anatomical features eliciting systolic movement of anterior mitral leaflet into LVOT [9].

The development of dynamic left ventricular outflow tract obstruction (DLVOTO) in states of hypercontractility is not infrequently observed during DSE. Although several studies investigating DLVOTO during DSE have been conducted, the clinical significance of DSE-provoked DLVOTO remains controversial. Pellikka et al., suggested that the development of dynamic intraventricular obstruction leads to hypotension during DSE [10].

It is importand to note that the development of dynamic LVO gradient during DSE was not associated with dobutamine induced-chest pain or shortness of breath [11].

Barletta et al., showed that intraventricular obstruction during DSE was clinically significant in patients without CAD who have unexplained reduced effort tolerance [12].

Post-myocardial infarction (MI) change in LV geometry due to opposition of hyperkinetic and hypokinetic regions after acute MI can sometimes result in SAM [13].

This is clinically important because vasodilator and inotropic agents used in cardiogenic shock can actually worsen hemodynamics in such patients. Judicious use of $\beta$-blocker may benefit such patients [9].

General anaesthesia, by its effect of vasodilation and hypovolemia, can sometimes provoke SAM even in the absence of any cardiac abnormality $[9,14]$.

In patients with hypertrophic cardiomyopathy (HCM), SAM is observed in mid systole, whereas in non-HCM hypertrophied ventricles, SAM peaks at the end of systole [15]. 
Pathophysiology of SAM clearly indicates that anatomically susceptible heart when subjected to hypovolemia, tachycardia, and reduced afterload can easily cause LV outflow obstruction with refractory hypotension and that correction of the hyperdynamic status, resolved LVOT obstruction in more than half of these patients without any further operative interventions [16]. It is important thus to avoid diuretic therapy in such patients.

He et al. [17], proposed that elongation of the anterior leaflet could be a mechanism for SAM -as at our case - and this is supported by echocardiographic evidence, showing the anterior mitral leaflet (AML) height is an important predictor of SAM [18]. Elongation of the MV leaflets can be pathological or may result from surgical correction. This evidence provides the rationale for the anterior valvuloplasty as a surgical technique to address moderate or severe SAM [19].

In patients with only mild SAM and MR, conservative medical therapy by volume administration, vasoconstriction, and $\beta$-blocker can be used to stabilize the patient.

After discussion of the treatment options with the patient, he decided to address the situation conservatively.

\section{References}

1. Sicari R, Nihoyannopoulos P, Evangelista A, Kasprzak J, Lancellotti $P$, et al. Stress Echocardiography Expert Consensus Statement Executive Summary: European Association of Echocardiography (EAE) (a registered branch of the ESC). Eur Heart J. 2009; 30: 278-289. PubMed: https://www.ncbi.nlm.nih.gov/pubmed/19001473

2. Carpentier A, Adams DH, Filsoufi F. Carpentier's Reconstructive Valve Surgery. Chapter 15. Maryland Heights: Saunders Elsevier, 2010. PubMed: https://www.ncbi.nlm.nih.gov/pmc/articles/ PMC3363100/

3. Maron BJ. Hypertrophic cardiomyopathy: a systematic review. JAMA. 2002; 287: 1308-1320. PubMed: https://www.ncbi.nlm. nih.gov/pubmed/11886323

4. Fujita $Y$, Kagiyama N, Sakuta $Y$, Tsuge M. Sudden hypoxemia after uneventful laparoscopic cholecystectomy: another form of SAM presentation. BMC Anesthesiol. 2015; 15: 51. PubMed: https://www. ncbi.nlm.nih.gov/pubmed/25927407

5. Routledge T, Nashef SA. Severe mitral systolic anterior motion complicating aortic valve replacement. Interact Cardiovasc Thorac Surg. 2005; 4: 486-487. PubMed: https://www.ncbi.nlm.nih.gov/ pubmed/17670463

6. Dorfman $T A$, Iskandrian $A E$, Aqel R. An unusual manifestation of Takotsubo cardiomyopathy. Clin Cardiol. 2008; 31: 194-200. PubMed: https://www.ncbi.nlm.nih.gov/pubmed/17847035

7. Maraud L, Gin H, Roudaut R, Aubertin J, Bricaud H. Echocardiographic study of left ventricular function in type 1 diabetes mellitus: hypersensitivity of beta-adrenergic stimulation. Diabetes Res Clin Pract. 1991; 11: 161-168. PubMed: https://www.ncbi.nlm.nih.gov/ pubmed/2036938

8. Henein MY, O'Sullivan C, Sutton GC, Gibson DG, Coats AJ. Stressinduced left ventricular outflow tract obstruction: a potential cause of dyspnea in the elderly. J Am Coll Cardiol. 1997; 30: 13011307. PubMed: https://www.ncbi.nlm.nih.gov/pubmed/9350931

9. Ibrahim M, Rao C, Ashrafian H, Chaudhry U, Darzi A, Athanasiou T. Modern management of systolic anterior motion of the mitral valve. Eur J Cardiothorac Surg. 2012; 41: 1260-1270. PubMed: https:// www.ncbi.nlm.nih.gov/pubmed/22290892

10. Pellikka PA, Oh JK, Bailey KR, Nichols BA, Monahan KH, Tajik AJ. Dynamic intraventricular obstruction during dobutamine stress echocardiography: A new observation. Circulation. 1992; 86: 14291432. PubMed: https://www.ncbi.nlm.nih.gov/pubmed/1423956

11. Luria D, Klutstein MW, Rosenmann D, Shaheen J, Sergey S, et al Prevalence and significance of left ventricular outflow gradient during dobutamine echocardiography. Eur Heart J. 1999; 20: 386-392. PubMed: https://www.ncbi.nlm.nih.gov/pubmed/10206385

12. Barletta G, Del Bene MR, Gallini C, Salvi S, Costanzo E, et al. The clinical impact of dynamic intraventricular obstruction during dobutamine stress echocardiography. Int J Cardiol. 1999; 70: 179-189. PubMed: https://www.ncbi.nlm.nih.gov/pubmed/10454307

13. Haley JH, Sinak LJ, Tajik AJ, Ommen SR, Oh JK. Dynamic left ventricular outflow tract obstruction in acute coronary syndromes: an important cause of new systolic murmur and cardiogenic shock. Mayo Clin Proc. 1999; 74: 901-906. PubMed: https://www.ncbi.nlm.nih.gov/ pubmed/10488794

14. Luckner G, Margreiter J, Jochberger S, Mayr V, Luger T, et al. Systolic anterior motion of the mitral valve with left ventricular outflow tract obstruction: three cases of acute perioperative hypotension in noncardiac surgery. Anesth Analg. 2005; 100: 1594-1598. PubMed: https://www.ncbi.nlm.nih.gov/pubmed/15920179

15. Doi YL, McKenna WJ, Oakley CM, Goodwin JF. 'Pseudo' systolic anterior motion in patients with hypertensive heart disease. Eur Heart J. 1983; 4 : 838-845. PubMed: https://www.ncbi.nlm.nih.gov/pubmed/6686523

16. Freeman WK1, Schaff HV, Khandheria BK, Oh JK, Orszulak TA, et al. Intraoperative evaluation of mitral valve regurgitation and repair by transesophageal echocardiography: incidence and significance of systolic anterior motion. J Am Coll Cardiol. 1992; 20: 599-609. PubMed: https://www.ncbi.nlm.nih.gov/pubmed/1512339

17. He S, Hopmeyer J, Lefebvre XP, Schwammenthal E, Yoganathan AP, et al. Importance of leaflet elongation in causing systolic anterior motion of the mitral valve. J Heart Valve Dis. 1997: 6: 149-159. PubMed: https://www.ncbi.nlm.nih.gov/pubmed/9130123

18. Shah PM, Raney. Echocardiographic correlates of left ventricular outflow obstruction and systolic anterior motion following mitral valve repair. J Heart Valve Dis. 2001; 10: 302-306. PubMed: https://www. ncbi.nlm.nih.gov/pubmed/11380091

19. Grossi EA, Galloway AC, Kallenbach K, Miller JS, Esposito R, et al. Early results of posterior leaflet folding plasty for mitral valve reconstruction. Ann Thorac Surg. 1998; 65: 1057-1059. PubMed: https://www.ncbi.nlm.nih.gov/pubmed/9564927 